\title{
Evaluation of the Ecological Benefits of Recycling Multiple Metals from Lithium Battery Saggars Based on Emergy Analysis
}

\author{
Wenbiao Zhang ${ }^{1}$, Zehong $\mathrm{Li}^{1,2, *}$, Shaopeng $\mathrm{Li}^{3, *}$, Suocheng Dong ${ }^{1,2}$, Bing Xia ${ }^{1} \mathbb{D}$ and Chunying Wang ${ }^{1,2}$ \\ 1 Institute of Geographic Sciences and Natural Resources Research, Chinese Academy of Sciences, \\ Beijing 100101, China; zhangwb@igsnrr.ac.cn (W.Z.); dongsc@igsnrr.ac.cn (S.D.); xiab.16b@igsnrr.ac.cn (B.X.); \\ wangchunying19@mails.ucas.ac.cn (C.W.) \\ 2 College of Resources and Environment, University of Chinese Academy of Sciences, Beijing 100049, China \\ 3 Institute of Process Engineering, Chinese Academy of Sciences, Beijing 100190, China \\ * Correspondence: lizehong@igsnrr.ac.cn (Z.L.); shpli@home.ipe.ac.cn (S.L.)
}

Citation: Zhang, W.; Li, Z.; Li, S.; Dong, S.; Xia, B.; Wang, C. Evaluation of the Ecological Benefits of Recycling Multiple Metals from Lithium Battery Saggars Based on Emergy Analysis. Sustainability 2021, 13, 10745 https://doi.org/10.3390/su131910745

Academic Editor: Rajesh Kumar Jyothi

Received: 11 August 2021

Accepted: 24 September 2021

Published: 27 September 2021

Publisher's Note: MDPI stays neutral with regard to jurisdictional claims in published maps and institutional affiliations.

Copyright: () 2021 by the authors. Licensee MDPI, Basel, Switzerland. This article is an open access article distributed under the terms and conditions of the Creative Commons Attribution (CC BY) license (https:// creativecommons.org/licenses/by/ $4.0 /)$.

\begin{abstract}
With the rapid development of China's new energy industry, the use of lithium-ion batteries has increased sharply, and the demand for battery cathode metals such as nickel, cobalt, and manganese has also increased rapidly. Scrapped ceramic saggars that are used to produce the cathode materials of lithium-ion batteries contain large amounts of nickel, cobalt, and manganese compounds; thus, recycling these saggars has high economic value and ecological significance. In this paper, the emergy method is used to analyze the ecological benefits of the typical Ni-Co-containing saggar recycling process in China. This paper constructs an ecoefficiency evaluation index for industrial systems based on emergy analysis to analyze the recycling of nickel and cobalt saggars. The ecological benefits are analyzed, and the following conclusions are drawn. (1) The Ni-Co-containing saggar recycling production line has good economic and ecological benefits. (2) The process has room for improvement in the energy use efficiency and clean energy use of the crystallization process and the efficiency of chemical use in the cascade separation and purification process. This study also establishes a set of emergy analysis methods and indicator system for the evaluation of the ecological benefit of the recycling industry, which can provide a reference for the evaluation of the eco-economic benefit of similar recycling industry processes.
\end{abstract}

Keywords: Ni-Co-containing saggars; eco-efficiency; life cycle assessment; recycling industry; metal recycling

\section{Introduction}

Lithium-ion batteries are currently a more popular new energy battery because of their high working voltage, high energy density, and long cycle life. Thus, lithium-ion batteries have a very high market value. Since the key component of lithium-ion batteries is cathode materials, cathode materials have been highly studied [1]. Nickel-cobalt-manganese ternary lithium-ion cathode materials perform better than any single-component cathode material. They overcome the problems of the poor stability of lithium manganese oxide and high cost of lithium cobalt oxide and improve the specific capacity and energy density of lithium-ion batteries. Therefore, the demand for ternary cathode materials is rapidly increasing at a rate of $20 \%$ per year. Ternary cathode materials will become the main power battery cathode materials for a period of time, and their market share will continuously increase [2]. With the increase in the use of nickel-cobalt-manganese ternary lithium batteries, the corresponding metal demand has increased rapidly [2]. Due to the scarcity of metal resources, including lithium, nickel, and cobalt, the reserves of related metals that exist on Earth will not be able to meet the growing demand for electric vehicles with ternary lithium batteries. If these metal resources can be recovered and recycled, then the problem of metal scarcity will be alleviated to a large extent. Thus, the recycling and reuse of the key metals of lithium-ion batteries have promising development prospects. 
The calcination of cathode materials for lithium batteries requires a ceramic saggar to contain the precursors of battery materials. During the calcining process, the battery cathode material precursor undergoes a chemical reaction at a high temperature to form a $\mathrm{LiNi}_{\mathrm{x}} \mathrm{Co}_{\mathrm{y}} \mathrm{Mn}_{1-\mathrm{x}-\mathrm{y}} \mathrm{O}_{2}$ battery cathode material. In this production process, the precursors of battery cathode materials are in contact with the inner wall of the refractory saggar. Under high-temperature calcining conditions, the cathode materials chemically react with the refractory material to form new multielement metal compounds on the surface of the saggar [3].

The saggar has to be scrapped after 5-20 uses. China produces approximately 8 million scrap Ni-Co-containing saggars each year (approximately $5 \times 10^{5}$ tons), which equals approximately 2000 tons of battery materials such as nickel, cobalt, manganese, and lithium [4]. Scrap saggars are generally discarded directly or used as the basic raw materials of refractory bricks and have not yet been fully utilized. However, scrap Ni-Co-containing saggars often contain nickel, cobalt, lithium, manganese, and other metal materials that are urgently needed by rechargeable batteries [5]; therefore, their direct discard has caused a significant waste of resources.

Although the pollution of the saggars is not serious, producing the metal material contained in it will cause serious damage to the environment during the process of mining, extraction, and smelting. In China, nickel mainly exists in the form of copper-nickel sulfide ore and laterite nickel ore. With the widespread use of nickel-containing batteries, the demand for nickel ore mining and smelting has increased. Nickel is mainly produced through electrolysis. The extraction of nickel ore produces a large amount of waste residue, and wastewater and waste gas are produced during electrolysis. For example, waste gas produced by the smelting process of nickel-cobalt sulfide ore contains large amounts of sulfur dioxide and chlorine-containing gas. If it is discharged into the atmosphere, it will cause serious air pollution. In addition to the small amounts of heavy metal ions such as $\mathrm{Ni}, \mathrm{Cu}, \mathrm{Co}$, and $\mathrm{Fe}$, the tailing water that is produced during the nickel smelting also contains a large amount of harmful elements such as $\mathrm{Na}^{+}, \mathrm{Cl}^{-}$, and $\mathrm{SO}_{4}{ }^{2-}$, which causes serious damage to groundwater [6]. Therefore, the recycling of waste Ni-Co-containing saggars has important economic and ecological significance regarding pollution.

The Institute of Process Engineering of the Chinese Academy of Sciences has established a lithium/nickel/cobalt/manganese multielement low-temperature reduction leaching technology and a high-silicon valuable element cascade separation/purification technology system for discarded saggars. This system has entered the pilot stage and has achieved the efficient recycling of key metal resources, thereby producing good economic benefits. However, the changes in the ecological impact caused by this process have not yet been analyzed.

Judging from the existing literature, the research on the recycling of nickel and cobalt metal is mainly concentrated on the recycling technology of the waste battery cathode materials [7-10], and research on the ecological impact of this recycling process is still relatively limited. Zackrisson (2010), Unterreiner (2016), and Raugei (2019) used life cycle assessment methods to compare the ecological effects of different solvents in automotive lithium batteries [11-13]. Richa (2017) analyzed the recycling of lithium batteries using ecological efficiency. It is believed that the recycling of lithium batteries can effectively reduce the environmental impact of ecotoxicity and other aspects and improve the life cycle ecological efficiency [14]. Wu (2019) compared the ecological footprints of different types of regenerated lithium batteries [15]. Other studies have focused on the ecological impact of related metals in the initial smelting process $[16,17]$. The related research on the calcination of the saggars of battery cathode materials mainly focuses on the characteristics of the saggars in the calcination process of the battery cathode material $[3,4]$. Research on the recycling of waste saggars that contain nickel and cobalt or its ecological impact is even scarcer.

Emergy theory and analysis methods were established by the famous American ecologist H.T. Odum in the 1980s [18] and were developed on the basis of energy analysis 
and research on the eco-economic system. Emergy theory is regarded as a bridge that connects ecology and economics and provides a new method for the measurement and comparative research in the quantitative analysis of eco-economic systems. Emergy analysis is based on converting different types and qualities of energy in the ecosystem or ecoeconomic system into the same standard emergy unit for measurement and analysis. By applying the new scientific concept and measurement standard of emergy and its conversion unit-emergy conversion rate (the energy value of a unit of energy or matter), it is possible to convert the various types of fluids and stored energy in the eco-economic system. The conversion of energy and matter into the same standard emergy unit, quantitative analysis and research on the utilization of natural resources in the system, and assessment of the sustainability of this developed recycling method can provide a scientific basis for formulating economic policies.

There are relatively few cases of emergy analysis used in industrial production analysis. S. Ulgiati and M.T. Brown (2002) used the emergy output rate and emergy to compare the environmental service value of different electricity production systems [18]. F. Giannetti et al. (2008) evaluated the eco-economic benefits brought by material savings in jewelry production by comparing emergy values and currency values [19]. C. Pereira and E. Ortega (2010) used the emergy method to analyze energy conversion in the production of ethanol from sugarcane [20]. In recent years, China's industrial emergy analysis has gradually received attention, such as the ecological impact in areas such as ecoindustrial parks [21-23], energy production [24,25], waste recycling [26], and urban material recycling [27]. Therefore, research has begun to emerge, and corresponding methods have been explored, thereby providing useful references to further deepen future research.

Based on the characteristics of emergy flow in industrial systems, this paper constructs an emergy analysis indicator system that performs a flow and efficiency evaluation, evaluates the ecological benefits of China's typical Ni-Co-containing saggar recycling process, and utilizes the emergy concept in different processes. The characteristics are analyzed and then suggestions are provided to direct future process improvement. The purpose of this research is to (1) evaluate the environmental impact of the entire life cycle of the Ni-Cocontaining saggar recycling process, (2) identify the environmental problems that still exist in the current production processes, and (3) propose further improvement directions. The important significance of this research lies in (1) building a method and indicator system for the emergy evaluation of the recycling industry to provide a new method of support for the research of emergy flow of recycling industry; (2) evaluating the ecological impact of the recycling of $\mathrm{Ni}$-Co-containing saggars, measuring the ecological benefits of the production, and determining the key links to further improve the ecological benefits of the process, and thus identify directions for further technological research and development. The structure of this article is as follows. The first part briefly introduces the research progress of Ni-Co-containing saggars and their emergy value, the second part describes the methods and data sources used in this article, the third part interprets the analysis results, and the fourth part is based on the analysis results. We provide corresponding conclusions and suggestions and discuss deficiencies and further research directions.

\section{Methods and Data}

\subsection{Overview of the Recycling Process of Ni-Co-Containing Saggars}

The pilot plant is a large lithium-ion battery cathode material saggar manufacturer located in Hunan Province, China, with a production capacity of 1.5 million saggars per year. The company cooperates with the Institute of Process Engineering of the Chinese Academy of Sciences to use recycled waste saggars to extract nickel, cobalt, and manganese precursors, along with lithium carbonate and other products through physical separation, reduction leaching, cascade separation, evaporative crystallization, and purification and to produce byproducts such as alum and potassium sulfate.

In the physical separation process, the inner surface of recycled waste saggars which contain multiple metals is first mechanically ground into powder. Then, this powder is 
separated from the saggars and enters the reduction and leaching process. The remaining saggars are used as a base aggregate for ceramic production. In the reduction and leaching process, the metal elements, including nickel, cobalt, lithium, and manganese, are immersed in an acid solution. The acid solution enters the cascade separation process to obtain primary products of important elements. The produced acid leaching residues are treated as solid waste by qualified institutions for further processing. The acid leaching solution enters the cascade separation step, a crude nickel-cobalt-manganese ternary precursor product is generated that goes to the purification step, and alum, aluminum hydroxide, and magnesium hydroxide are generated for sale. The remaining filtrate enters the crystallization step for further refinement. In the crystallization process, the filtrate is evaporated and crystallized to produce a crude product of lithium carbonate, and it produces potassium sulfate. The crude lithium carbonate enters the purification process, and the potassium sulfate is for direct sale. The remaining concentrated mother liquor enters the cascade separation process for the further extraction of metal elements. In the purification process, the nickel, cobalt, and manganese precursors and lithium carbonate are purified to battery quality and sold as the main products.

Due to the complexity of the production process, we chose the leading raw materialabandoned saggars - as a benchmark and determined that the functional unit of the study was $1000 \mathrm{~kg}$ of abandoned saggars. The material flow among the different production processes is shown in Figure 1.

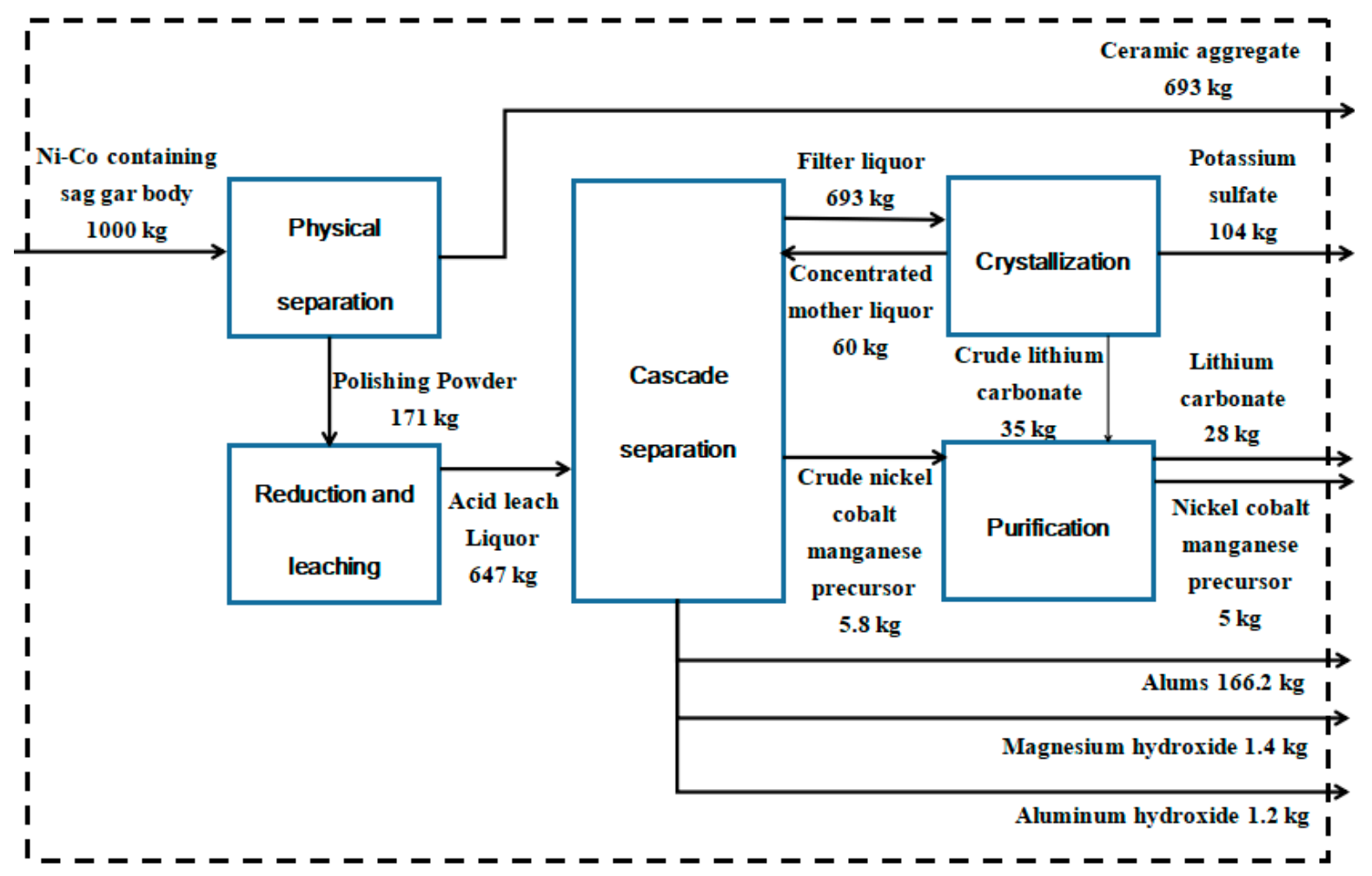

Figure 1. Scope of Ni-Co-containing saggar recovery emergy analysis.

Since the focus of this article is on the ecological impact of the production process, the research boundary range selects the "cradle to gate" model, that is, from the development of various raw materials to products. Additionally, the waste treatment process in the production process, along with all processes in the pilot stage, including physical separation, reduction and leaching, cascade separation, crystallization and purification, are considered. However, the ecological impact of equipment and infrastructure construction are not considered. Regarding the distribution of the environmental burden of common products, since this research focuses on the recycling of a single waste per unit mass, there is no 
problem of distribution among different products. In the selection of the cutoff method, since the nickel-cobalt saggar body used in this process is waste, it is considered that it does not bear the environmental burden distribution of the previous process.

\subsection{Emergy Analysis Method}

H.T. Odum (1987) defined emergy as the amount of another type of energy contained in flowing or stored energy [28]. He further explained that the emergy value is the total amount of available energy directly or indirectly placed into the application of the product or labor service formation process [29]. In essence, emergy is embodied energy [30]. Since any form of energy or matter is directly or indirectly derived from solar energy, "solar emergy" is usually used to measure the emergy value of various energy types or matter; for instance, the emergy value of flowing or stored energy or matter is its solar energy value [31]. The emergy value unit is solar emjoules (abbreviated as sej).

To compare different types of energy or matter, they need to be converted into a unified standard emergy unit; thus, the emergy conversion rate concept is proposed. The emergy conversion rate is the emergy value per unit of a certain type of energy or matter. Various forms of energy or materials are directly or indirectly derived from solar energy; therefore, the emergy value of different energy or materials can be measured by the conversion rate of solar energy. The amount of emergy contained in any flowing or stored energy is the solar emergy value contained in this energy or substance. Thus, based on their emergy values, the true values of various energy types or substances in the ecosystem can be measured and compared. The emergy conversion rate unit is solar emjoules/Joule, namely, sej/J or $\mathrm{sej} / \mathrm{g}$, and its basic expression is

$$
\mathrm{Em}=\mu P
$$

In the formula, Em is the solar emergy value in sej, $\mu$ is the solar emergy conversion rate, and $P$ is other available energy. By using the emergy analysis method, based on the material flow, the energy contained in the different grades, different types, and incomparable substances in the ecosystem is converted into a unified standard emergy unit for analysis, comparison, and research. Therefore, the different material flows can be evaluated. The contribution and status of various energy and material in the ecosystem can be combined with the established evaluation index system; thus, the ecological efficiency and economic benefits of the ecosystem can be comprehensively evaluated.

The basic steps of the emergy analysis of a system are as follows [32,33].

(1) Data collection and emergy analysis table compilation

Through investigation, measurement, and calculation, the material input and output data of Ni-Co-containing saggar recycling were collected and registered by category. Then, the main energy material sources and output items of the research system were listed. Through the emergy conversion rate according to Liu and Yang [33], the resource flow of each category in the emergy analysis table was calculated, each category of energy and matter was converted into a common emergy unit, and an emergy analysis table was compiled (Appendix A Table A1).

(2) Emergy system diagram

According to the "Emergy System Language" legend [34] used in the research report of Yan and Odum (2001), a detailed emergy system diagram was drawn to organize the collected data and construct not only the main components and relationships of the system, but also the relationship between the components of the research object and environment (Figure 2).

(3) Establishment of an emergy indicator system

By referring to the existing emergy analysis indicator system in various fields [25], a corresponding emergy analysis indicator system was established according to the characteristics of the industrial system of $\mathrm{Ni}$-Co-containing saggar recycling. Among them, the flow indicators include five items, including system input emergy (IMP), renewable resource 
emergy input $\left(\mathrm{R}_{\mathrm{i}}\right)$, nonrenewable resource emergy input $\left(\mathrm{N}_{\mathrm{i}}\right)$, system waste emergy $(\mathrm{WEM})$, and export emergy (EXP). The efficiency indicators include four items, namely, emergy yield rate (EYR), system waste emission rate (WEMR), environmental load rate (ELR), and emergy indicators of sustainable development (ESI). The specific meaning and calculation method of each indicator are shown in Table 1.

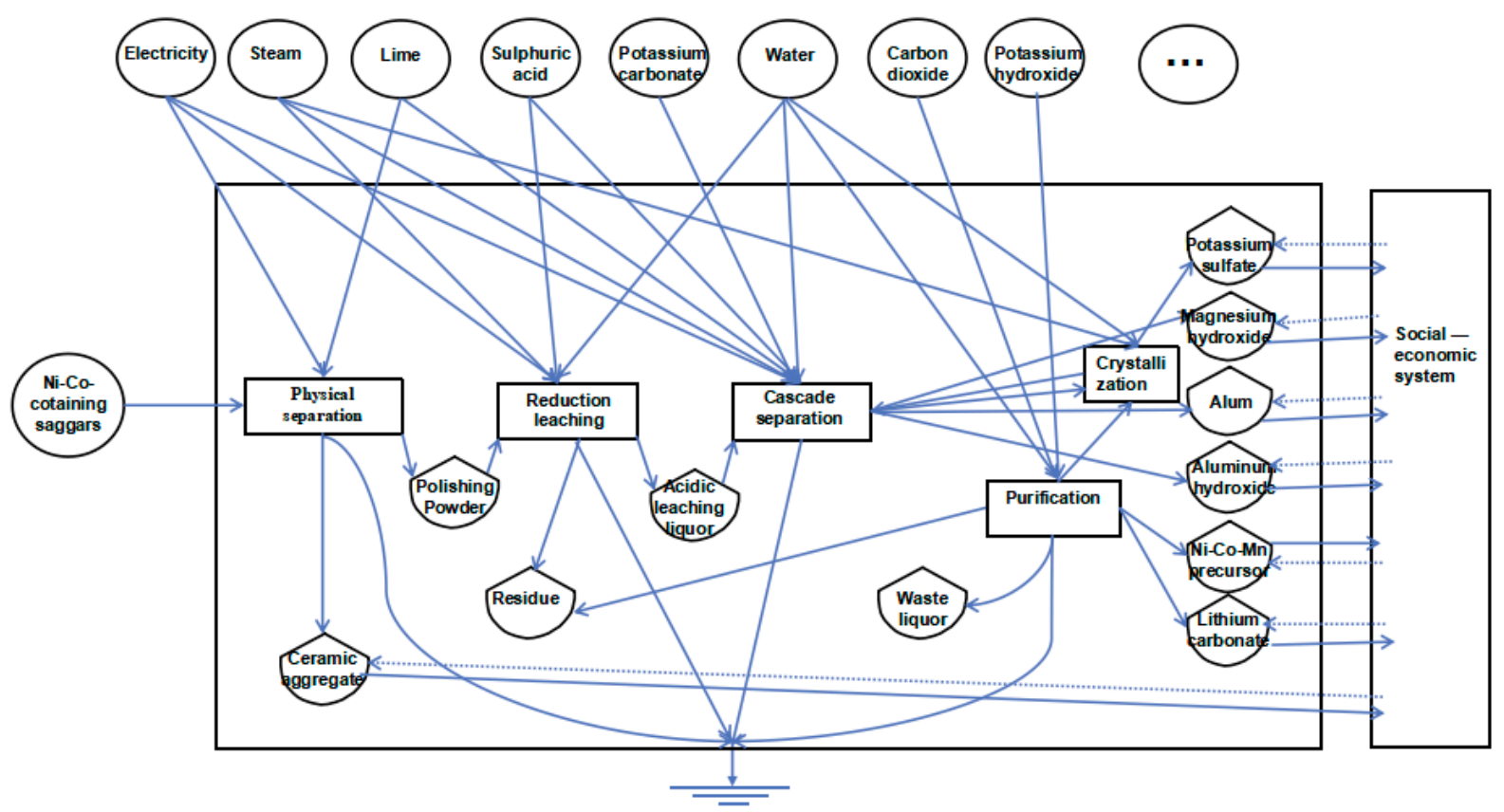

Figure 2. Emergy system diagram for recycling Ni-Co-containing saggars.

Table 1. Emergy analysis indicator system of Ni-Co-containing saggar recycling.

\begin{tabular}{|c|c|c|c|c|}
\hline Sort & Indicator & Unit & Calculation Formula & Note \\
\hline \multirow{5}{*}{ Flow indicator } & Input emergy (IMP) & sej & IMP & The sum of the emergy of each material input \\
\hline & $\begin{array}{l}\text { Renewable resource } \\
\text { emergy input } R_{i}\end{array}$ & sej & $\mathrm{R}_{\mathrm{i}}$ & $\begin{array}{l}\text { The sum of the emergy of each renewable } \\
\text { material input. }\end{array}$ \\
\hline & $\begin{array}{l}\text { Nonrenewable resource } \\
\text { emergy input } \mathrm{N}_{\mathrm{i}}\end{array}$ & sej & $\mathrm{N}_{\mathrm{i}}$ & $\begin{array}{l}\text { The sum of the emergy of each nonrenewable } \\
\text { material input. }\end{array}$ \\
\hline & $\begin{array}{l}\text { Waste emergy emission } \\
\text { (WEM) }\end{array}$ & sej & WEM & The total emergy of each waste emission. \\
\hline & Export emergy (EXP) & sej & EXP & The total emergy value of all products. \\
\hline \multirow{4}{*}{ Efficiency indicators } & Emergy yield rate (EYR) & - & EXP/IMP & $\begin{array}{l}\text { The ratio of product emergy to input emergy. A } \\
\text { higher emergy yield rate indicates that the } \\
\text { output is higher with the same input. }\end{array}$ \\
\hline & $\begin{array}{l}\text { Waste emergy emission } \\
\text { rate (WEMR) }\end{array}$ & - & WEM/EXP & $\begin{array}{l}\text { The ratio of dissipated emergy to total emergy } \\
\text { output. A higher system waste emission rate } \\
\text { indicates that the environmental cost of the } \\
\text { system is higher. }\end{array}$ \\
\hline & $\begin{array}{l}\text { Environmental load rate } \\
\text { (ELR) }\end{array}$ & - & $\mathrm{IMP} / \mathrm{R}_{\mathrm{i}}$ & $\begin{array}{l}\text { The ratio of the total energy value entered to } \\
\text { the renewable resources. The larger the value is, } \\
\text { the greater the environmental load. }\end{array}$ \\
\hline & $\begin{array}{l}\text { Emergy sustainable } \\
\text { development index (ESI) }\end{array}$ & - & EYR/ELR & $\begin{array}{l}\text { If ESI }<1 \text {, the system is a consumer system and is } \\
\text { unsustainable internally. When } 1<\text { ESI }<10 \text {, the } \\
\text { system has high sustainability. When ESI }>10 \text {, } \\
\text { the system has weak ability to use emergy and } \\
\text { the development level is relatively simple. }\end{array}$ \\
\hline
\end{tabular}

The unit sej is an abbreviation of solar emjoules, which is the normal unit of emergy. The value of any type of energy should be converted to the value of emergy in an emergy analysis. 
Compared with the emergy indicators of traditional ecosystems or industrial systems, a circular industrial system has its own distinctive features. According to the nature of the recycling industry system, this article regards recycled Ni-Co-containing saggars as a renewable resource. Since their industrial production system is highly open, almost all emergy is input from the outside of the system; therefore, both renewable and nonrenewable resources refer specifically to input resources. Furthermore, the calculation method of the environmental load factor changes from the usual (IMP $+N) /\left(R+R_{i}\right)$ to IMP $/ R_{i}$.

(4) System development evaluation and strategy analysis

Through an indicator analysis, this research provides a scientific basis for improving the ecological benefits of the industrial system and guides better operation and the sustainable development of the industrial system. The corresponding analysis results are shown in the third and fourth parts.

\subsection{Data Sources}

The data used in this article are mainly derived from the analysis data of the results of the pilot test conducted by the Institute of Process Engineering of the Chinese Academy of Sciences with a company in Hunan Province, China, including physical separation, reduction and leaching, cascade separation, crystallization, and purification. The emergy values of the various raw materials and emissions are from the Appendix of "Energy Analysis Theory and Practice" by Liu and Yang [33].

\section{Analysis of the Calculation Results}

\subsection{Economic Benefit Analysis}

The calculation method of eco-economic benefits is economic benefits minus resource consumption and environmental costs. By querying the market prices of raw materials, products, and the innocuous treatment of waste, all the external waste that is recycled and reused is converted into the eco-economic benefit generated by the production line according to the market price of the innocuous treatment of waste. On this basis, the total value and net value of the eco-economic benefit produced by the unit mass of $\mathrm{Ni}-$ Co-containing saggars produced by the production line were calculated. The calculation results are shown in Table 2 . For every $1000 \mathrm{~kg}$ of discarded saggars, the product value is CNY 3116, the resource input is CNY 777.82, and the environmental cost is CNY 206.15. By excluding the cost of resource consumption and environmental governance, an ecoeconomic benefit of CNY 2132.03 can be achieved, with a rate of return of $316 \%$. The ecological economic efficiency calculated in currency is thus very high. China produces approximately $5 \times 10^{5}$ tons of nickel and cobalt waste saggars every year. If all of them are processed in this manner, it can generate a revenue of CNY $1.1 \times 10^{9}$.

Table 2. Eco-economic benefit of recycling nickel-cobalt saggars.

\begin{tabular}{cc}
\hline Item & Eco-Economic Benefit (CNY/t) \\
\hline Resource input & 777.82 \\
Environmental cost & 206.15 \\
Other input & 0 \\
Value of products & 3116 \\
Profit & 2132.03 \\
Yield rate & 3.16 \\
\hline
\end{tabular}

\subsection{Emergy Analysis Results}

Table 3 shows that, in general, for every $1000 \mathrm{~kg}$ of saggars recovered in the nickelcobalt saggar recovery production line, the total input emergy is $1.60 \times 10^{15} \mathrm{sej}$. Most of this value comes from renewable resources (reaching $1.21 \times 10^{15}$ sej), namely, recycled waste saggars. The total amount of nonrenewable resources is $4.90 \times 10^{14}$ sej, which mainly includes reagents and fossil emergy inputs in various processes. Therefore, the adjustment 
of the structure and quantity of auxiliary materials and energy inputs should be the focus of further improving the environmental impact. Investment in nonrenewable resources is equivalent to only $40.5 \%$ of the renewable resources, which reflects the characteristics of the recycling industry. The emergy of the generated product is $2.23 \times 10^{15} \mathrm{sej}$, and the emergy value of the waste output is $2.08 \times 10^{11}$ sej. In terms of processes, the input emergy is the largest in the physical separation process, followed by cascade separation and crystallization; among them, the input of renewable resources is mainly concentrated in physical separation, and the nonrenewable resources are concentrated in cascade separation and crystallization. The most output product emergy is physical separation, followed by crystallization and cascade separation. The emergy emission of waste is mainly concentrated in the reduction and leaching process; thus, the discharge of acid mist and waste residue in this process should be further controlled.

Table 3. Calculation results of the emergy flow indicator of each process for recycling Ni-Co-containing saggars (unit: sej).

\begin{tabular}{cccccc}
\hline & IMP & $\mathbf{R}_{\mathbf{i}}$ & Ni & EXP & WEM \\
\hline Physical separation & $1.22 \times 10^{15}$ & $1.21 \times 10^{15}$ & $6.57 \times 10^{12}$ & $1.18 \times 10^{15}$ & 0 \\
Reduction and leaching & $1.18 \times 10^{14}$ & $1.71 \times 10^{11}$ & $1.18 \times 10^{14}$ & 0 & 20.4 \\
Cascade separation & $1.95 \times 10^{14}$ & $3.90 \times 10^{10}$ & $1.95 \times 10^{14}$ & $3.14 \times 10^{14}$ & 0 \\
Crystallization & $1.36 \times 10^{14}$ & $4.40 \times 10^{10}$ & $1.36 \times 10^{14}$ & $4.62 \times 10^{14}$ & 0 \\
Purification & $3.48 \times 10^{13}$ & $7.45 \times 10^{9}$ & $3.48 \times 10^{13}$ & $2.72 \times 10^{14}$ & $3.42 \times 10^{9}$ \\
Total & $1.70 \times 10^{15}$ & $1.21 \times 10^{15}$ & $4.90 \times 10^{14}$ & $2.23 \times 10^{15}$ & $2.08 \times 10^{11}$ \\
\hline
\end{tabular}

The calculation results of the emergy efficiency indicators are shown in Table 4 . The overall emergy yield rate of the production line is 1.31, which means that the emergy value of the product produced by this process is significantly greater than the input, and the process has good emergy benefits. The waste emission rate of the system is $9.31 \times 10^{-5}$, which indicates that the emergy utilization rate of the system is very high, and the proportion of waste energy dissipated is very small. These results are mainly due to the high recycling utilization of resources in the production process. The environmental load rate is 0.45 , and EYR $<1$, which suggest that the environmental load of the production line is small and that the environmental benefits are high. The sustainable development rate is $3.23(1<\mathrm{ESI}<10)$, which implies that the system has strong sustainability and emergy capability and is an ideal sustainable circulation system.

Table 4. Calculation results of the emergy efficiency indicator of each process for recycling Ni-Cocontaining saggars.

\begin{tabular}{cc}
\hline Indicator & Value \\
\hline EYR & 1.31 \\
WEMR & $9.31 \times 10^{-5}$ \\
ELR & 0.45 \\
ESI & 3.23 \\
\hline
\end{tabular}

\section{Conclusions and Recommendations}

This paper analyzes the ecological benefits of the recycling production line of $\mathrm{Ni}-$ Co-containing saggars by constructing an indicator system for evaluating the ecological benefits of industrial systems based on emergy analysis. The following conclusions can be drawn. (1) From the perspective of the eco-economic benefit, reduced resource consumption and environmental treatment costs can achieve ecological and economic benefits of CNY $2132.03 / t$, with a rate of return of 3.16 times, which demonstrates excellent ecological and economic benefits. (2) The emergy input-output rate of the recycling and utilization of $\mathrm{Ni}-$ Co-containing saggars is good. This result indicates that the total emergy output regarding resource consumption and pollution treatment is positive, which is consistent with the economic evaluation, and that the overall production is relatively good. Furthermore, 
the comprehensive economic-ecological benefits enhance the sustainability of economic operations. (3) Crystallization requires the most nonrenewable resources. This is mainly due to large energy consumption. The energy efficiency should be further improved while increasing the use of clean energy; additionally, cascade separation and purification consume more nonrenewable resources. Renewable resources are mainly due to the input of a large number of raw chemical materials. In the future, the accuracy of the use of raw chemical materials should be improved, and new environmentally friendly reagents should be developed. (4) The reduction and leaching process produces the largest waste emergy emission because the process produces acid mist and waste residues that contain calcium and magnesium. Therefore, it is necessary to increase the control of atmospheric emissions in this process and find a method for recycling waste residues.

Based on the characteristics of emergy flow in industrial systems, this paper constructs an emergy analysis index system that performs a flow rate and efficiency evaluation, evaluates the ecological benefits of a typical nickel-cobalt saggar recycling production line in China, and evaluates the characteristics of emergy input and output in different processes; thus, suggestions on the direction of future process improvement are obtained. This research is of great significance for accurately evaluating the ecological benefits of the production line and guiding the technical research direction to further improve the ecological benefits of the production line. At the same time, this paper constructs an emergy evaluation system for the ecological benefits of industrial production lines, especially recycling industrial production lines, which can be widely used in the evaluation of ecological benefits of various production lines. Because of the choice of the theme, this article did not conduct a complete evaluation of the emergy efficiency indicators for each production process. Furthermore, due to data limitations, the indicator system was unable to compare the ecological benefits of different production lines. This is also a direction of future research.

Author Contributions: W.Z.: conceptualization, methodology, writing—original draft preparation; Z.L.: reviewing, supervision; S.L.: data supplying, editing; S.D.: supervision; B.X.: methodology supporting; C.W.: data processing. All authors have read and agreed to the published version of the manuscript.

Funding: This research was conducted with support from the Key Deployment Project of the Chinese Academy of Sciences, "Evaluation of eco-efficiency of $\mathrm{Cu}-\mathrm{Ni}-\mathrm{Co}$ regenerated metal short process recycling industry chain", Grant Number ZDRWZS201812, the Project of Innovation Academy for Green Manufacture, Chinese Academy of Sciences Grant Number [IAGM-2019-A16], and the Training Program of the Major Research Plan of the National Natural Science Foundation of China, Grant Number 92062111.

Institutional Review Board Statement: The study did not involve humans or animals.

Informed Consent Statement: Not applicable.

Data Availability Statement: The data presented in this study are available on request from the corresponding author. The data are not publicly available due to business secrets of enterprises.

Conflicts of Interest: The authors declare no conflict of interest. 


\section{Appendix A}

Table A1. Emergy analysis table for recycling and utilizing nickel-cobalt saggars.

\begin{tabular}{|c|c|c|c|c|c|c|c|}
\hline Process & Sort & Material & Standard & Unit & Amount & $\begin{array}{l}\text { Emergy Transformity } \\
\text { (sej/Unit) }\end{array}$ & Emergy (sej) \\
\hline \multirow{5}{*}{ Physical separation } & \multirow{3}{*}{ Input } & Ni-Co-containing saggars & & $\mathrm{kg}$ & 1000.00 & $1.21 \times 10^{12}$ & $1.21 \times 10^{15}$ \\
\hline & & Water & & $\mathrm{kg}$ & 149.20 & $4.56 \times 10^{8}$ & $6.80 \times 10^{10}$ \\
\hline & & Electricity & & kwh & 8.25 & $7.96 \times 10^{11}$ & $6.57 \times 10^{12}$ \\
\hline & \multirow{2}{*}{ Output } & Ceramic aggregate & Moisture content $10 \%$ & $\mathrm{~kg}$ & 977.80 & $1.21 \times 10^{12}$ & $1.18 \times 10^{15}$ \\
\hline & & Polishing powder & Moisture content $30 \%$ & $\mathrm{~kg}$ & 171.40 & & 0.00 \\
\hline \multirow{8}{*}{ Reduction and leaching } & \multirow{6}{*}{ Input } & Polishing powder & Moisture content $30 \%$ & $\mathrm{~kg}$ & 171.40 & & 0.00 \\
\hline & & Sulfuric acid & $98 \%$ & $\mathrm{~kg}$ & 216.00 & $5.28 \times 10^{11}$ & $1.14 \times 10^{14}$ \\
\hline & & Leaching residue washing water & & $\mathrm{kg}$ & 160.00 & $4.56 \times 10^{8}$ & $7.30 \times 10^{10}$ \\
\hline & & Water & & $\mathrm{kg}$ & 216.00 & $4.56 \times 1^{08}$ & $9.85 \times 10^{10}$ \\
\hline & & Electricity & & kwh & 4.95 & $7.96 \times 10^{11}$ & $3.94 \times 10^{12}$ \\
\hline & & Steam & & $\mathrm{kg}$ & 10.00 & $2.04 \times 10^{7}$ & $2.04 \times 10^{8}$ \\
\hline & Output & Acidic leaching liquor & & $\mathrm{kg}$ & 647.00 & & 0.00 \\
\hline & Emission & Leaching residue & Moisture content $60 \%$ & $\mathrm{~kg}$ & 128.40 & $1.59 \times 10^{9}$ & $2.04 \times 10^{11}$ \\
\hline \multirow{11}{*}{ Cascade separation } & \multirow{6}{*}{ Input } & Potassium hydroxide & Industrial grade & $\mathrm{kg}$ & 55.60 & $1.86 \times 10^{12}$ & $1.03 \times 10^{14}$ \\
\hline & & Water & & & 85.60 & $4.56 \times 10^{8}$ & $3.90 \times 10^{10}$ \\
\hline & & Potassium sulfate mother liquor & Saturated solution & $\mathrm{kg}$ & 59.60 & & 0.00 \\
\hline & & Potassium sulfate & & $\mathrm{kg}$ & 20.00 & $4.44 \times 10^{12}$ & $8.88 \times 10^{13}$ \\
\hline & & Electricity & & kwh & 3.96 & $7.96 \times 10^{11}$ & $3.15 \times 10^{12}$ \\
\hline & & Steam & & $\mathrm{kg}$ & 12.00 & $2.04 \times 10^{7}$ & $2.45 \times 10^{8}$ \\
\hline & \multirow{5}{*}{ Output } & Alum & Industrial grade & $\mathrm{kg}$ & 166.20 & $1.86 \times 10^{12}$ & $3.09 \times 10^{14}$ \\
\hline & & Ni-Co-Mn precursor & crude product & $\mathrm{kg}$ & 5.80 & & 0.00 \\
\hline & & Filter liquor & & $\mathrm{kg}$ & 693.20 & & 0.00 \\
\hline & & Magnesium hydroxide & Industrial grade & $\mathrm{kg}$ & 1.40 & $1.86 \times 10^{12}$ & $2.60 \times 10^{12}$ \\
\hline & & Aluminum hydroxide & Industrial grade & $\mathrm{kg}$ & 1.20 & $1.86 \times 10^{12}$ & $2.23 \times 10^{12}$ \\
\hline
\end{tabular}


Table A1. Cont.

\begin{tabular}{|c|c|c|c|c|c|c|c|}
\hline Process & Sort & Material & Standard & Unit & Amount & $\begin{array}{c}\text { Emergy } \\
\text { Transformity } \\
\text { (sej/Unit) }\end{array}$ & Emergy (sej) \\
\hline \multirow{9}{*}{ Crystallization } & \multirow{5}{*}{ Input } & Filter liquor & & $\mathrm{kg}$ & 693.20 & & 0.00 \\
\hline & & Potassium carbonate & Industrial grade & $\mathrm{kg}$ & 66.00 & $1.86 \times 10^{12}$ & $1.23 \times 10^{14}$ \\
\hline & & Water & Pure water & $\mathrm{kg}$ & 96.40 & $4.56 \times 10^{8}$ & $4.40 \times 10^{10}$ \\
\hline & & Electricity & & kwh & 16.50 & $7.96 \times 10^{11}$ & $1.31 \times 10^{13}$ \\
\hline & & Steam & & $\mathrm{kg}$ & 198.00 & $2.04 \times 10^{7}$ & $4.04 \times 10^{9}$ \\
\hline & \multirow{4}{*}{ Output } & Potassium sulfate & Industrial grade & $\mathrm{kg}$ & 104.00 & $4.44 \times 10^{12}$ & $4.62 \times 10^{14}$ \\
\hline & & Concentrated mother liquor & & $\mathrm{kg}$ & 59.60 & & 0.00 \\
\hline & & Condensed water & & $\mathrm{kg}$ & 656.80 & $4.56 \times 10^{8}$ & $3.00 \times 10^{11}$ \\
\hline & & Crude lithium carbonate & Crude product & $\mathrm{kg}$ & 35.20 & & 0.00 \\
\hline \multirow{12}{*}{ Purification } & \multirow{8}{*}{ Input } & Crude Ni-Co-Mn precursor & Crude product & $\mathrm{kg}$ & 5.80 & & 0.00 \\
\hline & & Crude lithium carbonate & Crude product & $\mathrm{kg}$ & 35.20 & & 0.00 \\
\hline & & Carbon dioxide & & $\mathrm{kg}$ & 11.00 & $1.42 \times 10^{7}$ & $1.56 \times 10^{8}$ \\
\hline & & Water & Pure water & $\mathrm{kg}$ & 16.00 & $4.56 \times 1^{08}$ & $7.30 \times 10^{9}$ \\
\hline & & Ammonia & $25 \%$ & $\mathrm{~kg}$ & 9.00 & $1.86 \times 10^{12}$ & $1.67 \times 10^{13}$ \\
\hline & & Sodium hydroxide & & $\mathrm{kg}$ & 6.00 & $1.86 \times 10^{12}$ & $1.12 \times 10^{13}$ \\
\hline & & Electricity & & kwh & 2.00 & $7.96 \times 10^{11}$ & $1.59 \times 10^{12}$ \\
\hline & & Steam & & $\mathrm{kg}$ & 10.00 & $2.04 \times 10^{7}$ & $2.04 \times 10^{8}$ \\
\hline & \multirow{2}{*}{ Output } & $\mathrm{Ni}-\mathrm{Co}-\mathrm{Mn}$ precursor & Battery grade & $\mathrm{kg}$ & 5.00 & $2.93 \times 10^{13}$ & $1.47 \times 1^{014}$ \\
\hline & & Lithium carbonate & Battery grade & $\mathrm{kg}$ & 28.20 & $4.44 \times 10^{12}$ & $1.25 \times 10^{14}$ \\
\hline & \multirow{2}{*}{ Emission } & Calcium Magnesium slag & & $\mathrm{kg}$ & 1.80 & $1.59 \times 10^{9}$ & $2.86 \times 10^{9}$ \\
\hline & & Wastewater & & $\mathrm{kg}$ & 58.00 & $9.67 \times 10^{6}$ & $5.61 \times 10^{8}$ \\
\hline
\end{tabular}

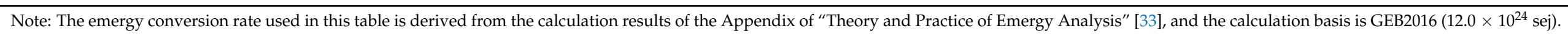




\section{References}

1. Yang, Z.; Lu, J.; Bian, D.; Zhang, W.; Yang, X.; Xia, J.; Chen, G.; Gu, H.; Ma, G. Stepwise Co-Precipitation to Synthesize Li $\mathrm{Ni}_{1 / 3} \mathrm{Co}_{1 / 3} \mathrm{Mn}_{1 / 3} \mathrm{O}_{2}$ One-Dimensional Hierarchical Structure for Lithium-Ion Batteries. J. Power Sources 2014, $272,144-151$. [CrossRef]

2. Li, Q.; Jiang, Q.; Li, L.; Feng, C. Synthesis and conditions of $\mathrm{Mn}_{x} \mathrm{Ni}_{\mathrm{y}} \mathrm{CozCO}_{3}$, a precursor of ternary cathode material. Inorg. Salt Ind. 2015, 47, 75-77.

3. Zhai, P.; Chen, L.; Yin, Y.; Li, S.; Ding, D.; Ye, G. Interactions between mullite saggar refractories and Li-ion battery cathode materials during calcination. J. Eur. Ceram. Soc. 2018, 38, 2145-2151. [CrossRef]

4. Liu, B. Lithium-Ion Battery Cathode Material Saggars Application Research; Qilu University of Technology: Jinan, China, 2015; pp. 34-35.

5. Li, J.; Chen, B.; Zhou, H. Exploration on Efficient and Comprehensive Utilization of Retired Power Battery. Battery China Network: The First International Summit on Power Battery Application in 2016. Available online: http://www.cbea.com/ content/ff808081582e454601583de1a5a7019a.jhtml (accessed on 10 August 2021).

6. Yu, H. Life Cycle Evaluation of Electrolytic Nickel Production; Kunming University of Science and Technology: Kunming, China, 2006; pp. 16-17.

7. Porvali, A.; Ojanen, S.; Wilson, B.; Serna-Guerrero, R.; Lundström, M. Nickel Metal Hydride Battery Waste: Mechanohydrometallurgical Experimental Study on Recycling Aspects. J. Sustain. Metall. 2020, 6, 78-90. [CrossRef]

8. Shi, H. Recovery and Reuse of $\mathrm{Li}(\mathrm{Co}, \mathrm{Ni}, \mathrm{Mn}) \mathrm{O}_{2}$ Cathode Material in Waste Lithium Ion Battery; Zhengzhou University: Zhengzhou, China, 2017; pp. 23-25.

9. Wang, L. Research on the Recovery and Recycling of Nickel from Waste Nickel-Hydrogen Batteries; Kunming University of Science and Technology: Kunming, China, 2017; pp. 12-14.

10. Yu, M. Study on Synthesizing Waste Nickel, Cobalt and Manganese Ternary Materials and Related Fine Chemicals by High Value of Cyclic Leaching Process; Beijing University of Chemical Technology: Beijing, China, 2018; pp. 27-29.

11. Zackrisson, M.; Avellán, L.; Orlenius, J. Life cycle assessment of lithium-ion batteries for plug-in hybrid electric vehicles-Critical issues. J. Clean. Prod. 2010, 18, 1519-1529. [CrossRef]

12. Unterreiner, L.; Juelch, V.; Reith, S. Recycling of Battery Technologies-Ecological Impact Analysis Using Life Cycle Assessment. Energy Procedia 2016, 99, 229-234. [CrossRef]

13. Raugei, M.; Winfield, P. Prospective LCA of the production and EoL recycling of a novel type of Li-ion battery for electric vehicles. J. Clean. Prod. 2019, 213, 926-932. [CrossRef]

14. Richa, K.; Babbitt, C.W.; Gaustad, G. Eco-Efficiency Analysis of a Lithium-Ion Battery Waste Hierarchy Inspired by Circular Economy. J. Ind. Ecol. 2017, 21, 715-730. [CrossRef]

15. Wu, H.; Gong, Y.; Yu, Y.; Huang, K.; Wang, L. Superior "green" electrode materials for secondary batteries: Through the footprint family indicators to analyze their environmental friendliness. Environ. Sci. Pollut. Res. 2019, 26, 36538-36557. [CrossRef]

16. Ali, U.; Malik, R.N.; Syed, J.H.; Mehmood, C.T.; Sanchez-Garcia, L.; Khalid, A.; Chaudhry, M.J.I. Mass burden and estimated flux of heavy metals in Pakistan coast: Sedimentary pollution and eco-toxicological concerns. Environ. Sci. Pollut. Res. 2015, 22, 4316-4326. [CrossRef]

17. El-Alfy, M.A.; El-Amier, Y.A.; El-Eraky, T.E. Land use/cover and eco-toxicity indices for identifying metal contamination in sediments of drains, Manzala Lake, Egypt. Heliyon 2020, 6, e03177. [CrossRef]

18. Ulgiati, S.; Brown, M.T. Quantifying the environmental support for dilution and abatement of process emissions: The case of electricity production. J. Clean. Prod. 2002, 10, 335-348. [CrossRef]

19. Giannetti, B.F.; Bonilla, S.H.; Silva, I.; Almeida, C.M.V.B. Cleaner production practices in a medium size gold-plated jewelry company in Brazil: When little changes make the difference. J. Clean. Prod. 2008, 16, 1106-1117. [CrossRef]

20. Pereira, C.L.; Ortega, E. Sustainability assessment of large-scale ethanol production from sugarcane. J. Clean. Prod. 2010, 18, 77-82. [CrossRef]

21. Geng, Y.; Zhang, P.; Ulgiati, S.; Sarkis, J. Emergy analysis of an industrial park: The case of Dalian, China. Sci. Total. Environ. 2010, 408, 5273-5283. [CrossRef] [PubMed]

22. Wang, L.; Li, Z.; Ni, W. Emergy evaluation of polygeneration systems. Front. Energy Power Eng. China 2007, 1, 223-227. [CrossRef]

23. Wang, L.; Li, Z.; Feng, M.; Zuo, X.; Hao, X.; Xu, Z.; Ni, W. Emergy Evaluation of Double Gas Polygeneration Systems. J. Chin. Soc. Power Eng. 2010, 30, 798-803.

24. Li, T.; Song, Y.; Shen, J. Clean Power Dispatching of Coal-Fired Power Generation in China Based on the Production Cleanliness Evaluation Method. Sustainability 2019, 11, 6778. [CrossRef]

25. Cao, K.; Feng, X. Emergy analysis and comparison of methanol synthesis processes using different feedstocks. Chem. Ind. Eng. Prog. 2006, 1461-1466, 1483. [CrossRef]

26. Yu, J.; Yang, J.; Jiang, Z.; Zhang, H.; Wang, Y. Emergy based sustainability evaluation of spent lead acid batteries recycling. J. Clean. Prod. 2020, 250, 1167-1194. [CrossRef]

27. Zhang, W.; Wang, J.; LI, Y. A Research on the Sustainable Development Level of Kashgar Based on Energy Analysis. Environ. Sustain. Dev. 2014, 39, 161-164. [CrossRef]

28. Odum, H. Blisset M E C. Ecology and Economy: Emergy Analysis and Publicly in Texas; University of Texas-School of Public Affairs and Texas Dept of Agriculture: Austin, TX, USA, 1987; pp. 22-24. 
29. Odum, H. Environmental Accounting Emergy and Environmental Decision Making; John Wiley and Sons: New York, NY, USA, 1996; pp. 17-19.

30. Lan, S.; Qin, P.; Lu, H. Emergy Analysis of Eco Economic System; Chemical Industry Press: Beijing, China, 2002 ; pp. $27-42$.

31. Lan, S.; Qin, P. Emergy analysis of ecosystems. Chin. J. Appl. Ecol. 2001, 12, 129-131.

32. Li, H.; Liao, Y.; Yan, M. Emergy Analysis on the Ecological -economic System of Jiangxi Province. Acta Agric. Univ. Jiangxiensis 2003, 25, 93-98. [CrossRef]

33. Liu, G.; Yang, Z. Emergy Analysis Theory and Practice: Ecological Economic Accounting and Urban Green Management; Science Press: Beijing, China, 2018; pp. 362-372.

34. Yan, M.; Odum, T. New Visual Angle to View Eco-Economic System-Emergy Evaluation Case studies of Chinese Regional Eco-Economic System; China Zhigong Publishing House: Beijing, China, 2001; pp. 56-61. 